Archived version from NCDOCKS Institutional Repository http://libres.uncg.edu/ir/asu/

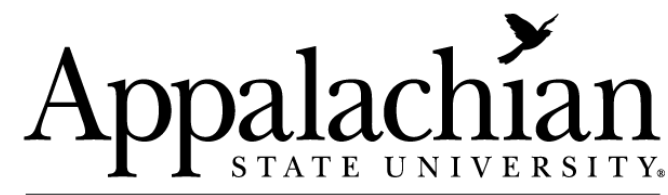

B O O N E, NORT H C A R O L I A

\section{Perceived Stress and ADHD Symptoms in Adults}

\author{
By: Courtney A. Rocheleau, Martha A. Combs, Will H. Canu, \\ Joshua J. Broman-Fulks and David C. Nieman
}

\begin{abstract}
Given that ADHD has been linked to dysfunction across development and in many life domains, it is likely that individuals experiencing these symptoms are at increased risk for experiencing stress. The current study examines the association between ADHD and other psychiatric symptoms and perceived stress in a community sample of adults. Perceived stress data collected from 983 participants ( $\mathrm{M}$ age $=45.6$ years) were analyzed primarily via hierarchical multiple regression using ADHD symptom clusters, demographic variables, and anxiety and depression scale variables as predictors. ADHD symptoms positively associated with perceived stress. Inattention and sluggish cognitive tempo (SCT), as opposed to hyperactivityimpulsivity and newly proposed executive dysfunction symptoms, were the most consistent predictors. These findings reinforce that the experience of ADHD symptoms in adulthood is associated with stress and suggest that SCT could play an important role in assessing risk for negative adult outcomes.
\end{abstract}

Courtney A. Rocheleau, Martha A. Combs, Will H. Canu, Joshua J. Broman-Fulks and David C. Nieman (2015) "Perceived Stress and ADHD Symptoms in Adults" Journal of Attention Disorders volume 19(5) pp. 425-434 [DOI: 10.1177/1087054712459558] Version of Record Available from (jad.sagepub.com) 


\title{
Perceived Stress and ADHD Symptoms in Adults
}

\author{
Martha A. Combs',2, Will H. Canu', Joshua J. Broman-Fulks', \\ Courtney A. Rocheleau ${ }^{1,3}$, and David C. Nieman'
}

\begin{abstract}
Objective: Given that ADHD has been linked to dysfunction across development and in many life domains, it is likely that individuals experiencing these symptoms are at increased risk for experiencing stress. The current study examines the association between ADHD and other psychiatric symptoms and perceived stress in a community sample of adults. Method: Perceived stress data collected from 983 participants $(M$ age $=45.6$ years) were analyzed primarily via hierarchical multiple regression using $A D H D$ symptom clusters, demographic variables, and anxiety and depression scale variables as predictors. Results and Conclusion: ADHD symptoms positively associated with perceived stress. Inattention and sluggish cognitive tempo (SCT), as opposed to hyperactivity-impulsivity and newly proposed executive dysfunction symptoms, were the most consistent predictors. These findings reinforce that the experience of ADHD symptoms in adulthood is associated with stress and suggest that SCT could play an important role in assessing risk for negative adult outcomes.
\end{abstract}

\section{Keywords}

stress, ADHD, adults, sluggish cognitive tempo

In the past, it was commonly believed that ADHD affected only children and adolescents. Empirical research, however, has shown ADHD to be a lifelong disorder, with ADHD traits continuing into adulthood in approximately $60 \%$ to $78 \%$ of diagnosed children and adolescents (Biederman, Petty, Evans, Small, \& Faraone, 2010; Sibley et al., 2012; Sobanski, Schredl, Kettler, \& Alm, 2008) and affecting 4.4\% of adults in the United States (Kessler et al., 2006). ADHD is primarily characterized by two symptom clusters, inattention (IA) and hyperactivity-impulsivity (HI), and is divided into diagnostic subtypes based on expressed symptoms in these clusters. The two most prevalent types are Predominantly Inattentive (ADHD-IA) and Combined (i.e., prominent HI and IA symptoms), with Predominantly Hyperactive (ADHDHI) type being less prevalent and potentially developmentally limited to childhood (Chhabildas, Pennington, \& Willcutt, 2001).

Due in part to the fact that ADHD manifests somewhat differently in adults than it does in children (e.g., robust evidence that $\mathrm{HI}$ tends to diminish across the life span; Biederman, Mick, \& Faraone, 2000), efforts to develop appropriate adult diagnostic criteria have emerged (Barkley, 2006). Barkley and colleagues (Barkley, Murphy, \& Fischer, 2008) proposed new criteria for the diagnosis of ADHD in adults, focusing largely on executive functioning deficits and contending that these identify ADHD in adulthood better than the Diagnostic and
Statistical Manual of Mental Disorders (DSM-IV-TR; American Psychiatric Association [APA], 2000) criteria (see exception in Fedele, Hartung, Canu, \& Wilkowski, 2010). Sluggish cognitive tempo (SCT), characterized by sluggishness, passivity, confusion, and hypoactivity, may also be considered a candidate indicator of ADHD. In children, SCT has been linked most robustly to ADHD-IA (Barkley, 2006; Carlson \& Mann, 2002; Hartman, Wilcutt, Rhee, \& Pennington, 2004). These symptoms appear to oppose those associated with ADHD-HI and, due partly to the fact that $\mathrm{HI}$ is not as prevalent in the adult population, SCT is considered to be of potential importance in the identification of ADHD; this is particularly so for the Predominantly Inattentive type (Carlson \& Mann, 2002). In fact, recent research suggests that approximately $68 \%$ of adults with ADHD-IA may also display symptoms of SCT (Barkley, 2011). However, it has also been suggested that SCT, in itself, may represent a disorder independent of

\footnotetext{
'Appalachian State University, Boone, NC, USA

${ }^{2}$ University of Alabama, Tuscaloosa, USA

${ }^{3}$ Metropolitan State University of Denver, CO, USA

Corresponding Author:

Will H. Canu, Department of Psychology, Appalachian State University, 222 Joyce Lawrence Lane, Boone, NC 28608, USA.

Email: canuwh@appstate.edu
} 
ADHD altogether (Barkley, 2011; Milich, Balentine, \& Lynam, 2001).

\section{Maladjustment Associated With ADHD and Potential Stress}

Regardless of the specific type of ADHD, its symptoms are generally associated with pervasive and persistent impairment across several domains of life (Whalen, Jamner, Henker, Delfino, \& Lozano, 2002), which in turn seems quite likely to evoke elevated stress. Academic difficulty for those affected by the disorder is common and can begin at an early age. Studies have shown that children with ADHD, when compared with those without, have a higher incidence of learning problems (Loe et al., 2008) and need for academic assistance (Biederman et al., 1998), and lower overall academic achievement (McConaughy, Volpe, Antshel, Gordon, \& Eiraldi, 2011). College-age ADHD adults have demonstrated significantly lower task performance in the areas of concentration $(d=.40)$, motivation $(d=1.20)$, and information processing $(d=.61$; Reaser, Prevatt, Petscher, \& Proctor, 2007), and undergraduates without ADHD have generally been shown to be better adjusted to the academic and social demands of higher education than their affected peers (Blase et al., 2009). Many of the deficits that impact those with ADHD academically, such as impaired attention, interpersonal skills, initiative, and task persistence, also hinder occupational functioning (Hill \& Petty, 1995; Sibley et al., 2012), which becomes increasingly evident as ADHD adolescents grow into adulthood and take on jobs requiring more skill and responsibility (Barkley, 2006). One study found that $32 \%$ of an ADHD sample had failed to complete high school, which, when considering this rate approximately doubles that of nondiagnosed peers, helps to explain why adults with ADHD tend to have lower status occupations (Weiss, Hechtman, Milroy, \& Perlman, 1993) and lower general socioeconomic status (Barkley, 2006). Overall, empirical findings reinforce that negative impact due to clinically elevated IA, hyperactivity, and impulsivity continues in adult academic and vocational functioning.

A large body of evidence also suggests that children with ADHD experience more social dysfunction than their nondiagnosed peers (e.g., Gaub \& Carlson, 1997; see review in Canu \& Carlson, 2004) and have fewer friendships than children without the disorder (Hoza et al., 2005). Although ADHD-related social difficulties usually begin in childhood and have been found to continue into adolescence, affected adults also appear to be at heightened risk for social adjustment difficulties (Bagwell, Molina, Pelham, \& Hoza, 2001), including struggles with forming and maintaining intimate relationships (Young \& Gudjonsson, 2006).

Prior research has suggested that the litany of problems associated with ADHD can lead to heightened personal distress. For instance, up to $25 \%$ of children diagnosed with
ADHD also meet criteria for an anxiety disorder, and elevated anxiety seems overrepresented in the adult ADHD population as well (Barkley, 2006). In addition, recent research has documented individuals with diagnosed and untreated ADHD to have dramatically higher risk for not only the anxiety disorders but also mood disorders and alcohol dependence, with odds ratios ranging from approximately three (major depression) to eight (bipolar disorder; Able, Johnston, Adler, \& Swindle, 2007; Friedrichs, Igl, Larsson, $\&$ Larsson, 2012). Considering many of the core symptoms and related difficulties inherent to ADHD (e.g., academic, interpersonal dysfunction), the likelihood that this population would experience chronically heightened stress seems quite substantial.

\section{Defining Stress}

Stress is generally conceptualized as a negative cognitiveemotional state resulting from an individual's perception of difficulty adjusting to or managing life events (Taylor, 2006). Specifically, stress results from an individual's appraisal that the demands of the environment are taxing or exceed the individual's resources and thereby endanger the person's well-being (Lazarus, 1993). When presented with a stressor, an individual experiences physiological, cognitive, and behavioral changes that facilitate coping and problem solving. However, the construct of stress is subjective; its manifestation varies across individuals, with positive or negative stressor appraisals and physiological differences contributing to the experience of stress (Taylor, 2006).

Although stress often serves as a beneficial warning to the body regarding potential danger or challenge, elevated stress levels have been linked to negative life and health outcomes. Chronic stress has been associated with increased risk of developing illness (Cohen, Tyrrell, \& Smith, 1993), decreased efficiency of overall immune functioning (see review in Kemeny \& Schedlowski, 2007), the development of cardiovascular disease (Goble \& Le Grande, 2008), and greater susceptibility to infection (Cohen, 2005). In addition, long-term stress has been related to accelerated aging (Simon et al., 2006) and the development of overeating behaviors and obesity (Dallman et al., 2003). As such, chronic psychological conditions that are accompanied by elevated stress are of particular concern.

\section{ADHD and Stressor Prevalence}

Given the host of difficulties ADHD sufferers must cope with (e.g., academic struggles, interpersonal rejection, comorbid mood or anxiety issues, as described above), it is logical to posit that most affected individuals live with elevated subjective stress. Generally speaking, the impact of higher stress related to ADHD seems likely to not only be limited to the sufferer but also probably affects family, friends, and one's 
personal environment. ADHD exacts numerous costs (i.e., behavioral interventions, medication costs, time off from work; Riley, Lyman, et al., 2006) on families of diagnosed children and affected adults, and the stress associated with such costs ultimately affects the environment (e.g., family living situation; Beitchman, Inglis, \& Schachter, 1992; Lange et al., 2005). In 2000 alone, close to US $\$ 3.7$ billion was lost due to ADHD-related costs, including unemployment of individuals with ADHD or family members who miss work due to their children having ADHD (Birnbaum et al., 2005), illustrating the magnitude of economic stress incurred within a family. Although families and others (e.g., employers) may at times be supportive of affected individuals, a large-scale examination of adult twins in Sweden suggests that those with ADHD are at nearly twice the risk of experiencing significant stressors such as divorce, family problems, and financial loss (Friedrichs et al., 2012). In sum, the body of literature suggests that ADHD is a disorder that is likely to be associated with the experience of numerous objective stressors across childhood and into one's adult years; the experience of these stressors, however, may be even more painful for those with ADHD than their nondiagnosed peers, given inherent stress response differences.

\section{Stress Reactivity and ADHD}

Research regarding the ADHD-personal stress association has focused on physiological stress responses as well as the extent of subjective daily stressors. The physiological stress response and stress experience in adult ADHD patients has been examined by comparing the event-mediated arousal of adults with ADHD with that of nondiagnosed adults. Overall, research has demonstrated ADHD adults to have elevated physiological stress responses (as measured by salivary cortisol levels) and a higher level of self-reported subjective stress when compared with nondiagnosed controls (Hirvikoski, Lindholm, Nordenstrom, Nordstrom, \& Lajic, 2009; Lackschewitz, Huther, \& Kroner-Herwig, 2008). In fact, the levels of stress for adults diagnosed with ADHD appear elevated in the presence of a stressor and in anticipation of it. In addition, in one study, measures of physiological stress demonstrated a greater difficulty in recovering from elevated stress levels in the ADHD group (Lackschewitz et al., 2008), indicating that persons with ADHD may also face challenges in recovering from stress. These data provide further evidence for a possible predisposition of ADHD individuals to higher stress.

\section{Stress Management Skills and ADHD}

Nearly two decades ago, inability to tolerate stress was proposed by Wender (1995) as an additional characteristic for the diagnosis of ADHD. Indeed, research has suggested that individuals with ADHD demonstrate diminished coping in the face of stress (Riley, Spiel, et al., 2006), which likely exacerbates the impact of stressors. Children with ADHD have been found to demonstrate lower self-esteem than nondiagnosed peers and, likely as a result, to engage in less active approaches to solving interpersonal problems (Riley, Spiel, et al., 2006). The symptoms of IA, hyperactivity, and impulsivity are linked to lower levels of planning, organization, and self-control (Davis, Levitan, Smith, Tweed, \& Curtis, 2006), which are critical to successful stress management. Individuals with ADHD, especially those with prominent hyperactive or impulsive traits, tend to act immediately when presented with a complex stimulus rather than to engage in problem solving (Davis et al., 2006). If the stimulus is considered by the individual to be stressful, his or her impulsive response likely will not be well planned, and therefore is unlikely to actually alleviate stress.

\section{Summary and Rationale for the Current Study}

A variety of life experiences in childhood and adulthood are negatively impacted by the presence of ADHD symptoms. As noted above, academic and occupational difficulties are common (Reaser et al., 2007; Weiss et al., 1993), as are interpersonal problems in childhood (Hoza et al., 2005) and adulthood (Barkley, 2006). Furthermore, individuals with ADHD are at elevated risk for general emotional problems, including mood and anxiety disorders (Able et al., 2007; Friedrichs et al., 2012), as compared with nondiagnosed peers, and those with ADHD have been shown to be more physiologically reactive to stress (Lackschewitz et al., 2008). In sum, the impact of ADHD is significant and plays a considerable role in the ADHD individual's experience of psychological and physiological well-being.

To date, however, research focusing on the health-andhappiness outcomes associated with ADHD has largely focused on children. With almost 1 in 20 adults in the United States affected by ADHD (Kessler et al., 2006), it is clear that this older segment of the ADHD population warrants similar attention. Therefore, this study aimed to examine the impact that ADHD symptoms have on the psychological well-being of adults. Specifically, perceived stress was assessed as a dependent variable in an adult, community-recruited sample that was indexed by adult ADHD traits. Based on previous research, the comparison of all ADHD traits with level of perceived stress was expected to yield a positive association.

\section{Method}

\section{Participants}

A sample of 1,044 nonclinical, community participants from western North Carolina was recruited via newspaper, 
Table I. Descriptive Statistics: Demographic, Independent, and Dependent Variables.

\begin{tabular}{lcc}
\hline Variable & Descriptive/M (SD) & Observed range \\
\hline Gender & $60.7 \%$ female & \\
Age & $45.56(16.19)$ years & $18-85$ \\
Education & $15.53(2.8)$ years & $2-20$ \\
Depression & $52.35(10.09)$ & $0-80$ \\
Anxiety & $51.21(10.59)$ & $0-80$ \\
IA & $5.14(4.13)$ & $0-26^{\mathrm{a}}$ \\
HI & $4.92(3.79)$ & $0-27$ \\
SCT & $2.27(1.79)$ & $0-9$ \\
BMF & $3.06(2.53)$ & $0-16^{\mathrm{a}}$ \\
PSS & $13.69(6.39)$ & $0-38^{\mathrm{a}}$ \\
\hline
\end{tabular}

Note: IA = DSM-IV Inattention scale score; HI= DSM-IV Hyperactivity $/$ Impulsivity scale score; SCT = Sluggish Cognitive Tempo scale score; BMF = supplemental Barkley-Murphy-Fischer ADHD criteria; PSS = Perceived Stress Scale score.

aMaximum possible score differs from highest observed score as follows: $\mathrm{IA}=27, \mathrm{BMF}=18, \mathrm{PSS}=40$

radio, and online advertising to participate in a 3-month, randomized double-blind trial examining the effects of an antioxidant on physical and psychological health. An incentive of US $\$ 300$ was paid to participants for completion of the entire study, which involved adherence to an antioxidant (or placebo) supplement regimen and baseline, intra- and posttrial physiological, cognitive, and other psychological assessments. The sample spanned ages 18 to 85 and was limited to participants who were noninstitutionalized, not pregnant, and nonlactating. No other exclusion criteria were used. The baseline survey included the measures used in the current study. Of the 1,044 participants recruited for the study, 983 (94.2\% of original sample) completed ADHD and stress-related data, and were included herein $(60.7 \%$ female participants, $95.6 \%$ Caucasian). Age breakdown of the sample is as follows: $37.6 \%$ young adult (18-40 years), $49.9 \%$ middle-aged (41-65), and $12.4 \%$ retirement age (66-85). The sample was highly educated relative to the general U.S. population, with $81.6 \%$ having completed at least some college. Data were collected in 2008, with 473 people participating in the spring (Cohort 1 ) and 510 people participating in the fall (Cohort 2). Additional details regarding the sample's composition are provided in Table 1.

\section{Measures}

Current Symptom Scale (CSS). This self-report measure consists of 18 items tapping the inattentive and hyperactiveimpulsive symptoms of ADHD as defined in the DSM-IV-TR (APA, 2000), and references behavior in the past 6 months (Barkley \& Murphy, 2006). Example items include, "Fidgeted with hands or feet or squirmed in seat" (HI) and "Didn't listen when spoken to directly" (IA). Responses are made on a 4-point Likert-type scale $(0=$ never or rarely, $3=$ very often). A single item was added to assess overall impairment experienced by participants due to ADHD symptoms using the same scale. In addition, three items tapping SCT, a cognitive style associated with the Inattentive type of ADHD (see above for description; Carlson \& Mann, 2002), were also added to each measure to examine the potential association of this distinct trait on health outcomes. In the current sample, internal reliability for all scales was adequate, as assessed by Cronbach's alpha $(\mathrm{IA}=.86, \mathrm{HI}=.78, \mathrm{SCT}=.73)$.

Barkley-Murphy-Fischer (BMF) Proposed Adult ADHD Criteria Scale. This nine-item self-report measure has recently been shown in a large adult sample to more effectively distinguish ADHD from non-ADHD subgroups than the DSM$I V$-TR ADHD criteria (Barkley et al., 2008). Three items included in this symptom set are duplicates of DSM-IV-TR criteria; as these were assessed using the Current Symptom Scale (see above) and included in the IA and HI scales, they were dropped for the purposes of independent analysis, creating a six-item form. Responses are given on a 4-point scale similar to the Current and Childhood Symptom Scales (Barkley \& Murphy, 2006) and reference the past 6 months; sample items include, "Have difficulty stopping activities or behavior when I should do so" and "Have trouble doing things in the proper order or sequence." Internal consistency of the six-item Adult ADHD Criteria Scale used in this study was satisfactory $(\alpha=.70)$.

Perceived Stress Scale (PSS). This frequently used measure consists of 10 items designed to assess the degree to which common life situations are deemed stressful, referencing the past month (e.g., "In the last month, how often have you been upset because of something that happened unexpectedly?"). Responses are made on a 5 -point scale $(0=$ never, $4=$ very often). The PSS (Cohen, Kamarck, \& Mermelstein, 1983 ) has previously been shown to have high internal reliability ( $\alpha=.85$; Lavoie \& Douglas, 2012) and to positively correlate with physical symptoms of anxiety (Cohen et al., 1983); using data from the second cohort of the current study $(n=510)$, internal reliability of the scale was determined to be similarly high $(\alpha=.88)$. Scoring of a paper-and-pencil version of the PSS for the first cohort was such that internal reliability was not calculable for that subsample.

Brief Symptom Inventory (BSI). This commonly used 53-item, self-report measure consists of nine scales and three global indices designed to assess presence and severity of a variety of psychological symptoms (e.g., depression, anxiety). Examples include, "Thoughts of ending your life," "Feelings of worthlessness" (depression symptoms), "Feeling fearful," and "Nervousness or shakiness inside" (anxiety symptoms). Symptoms are assessed by frequency or severity of symptom experience on a 5-point Likert-type scale $(0=$ not at all, $4=$ extremely $)$. Internal consistency reliability for the depression and anxiety scales are .85 and .81 , respectively, whereas test-retest reliabilities are .84 and 
Table 2. Pearson's Correlations Between Independent Variables and Perceived Stress for Entire Sample (Both Cohorts).

\begin{tabular}{|c|c|c|c|c|c|c|c|c|c|}
\hline Variables & Age & Education & Depression & Anxiety & IA & $\mathrm{HI}$ & $\mathrm{SCT}$ & $\mathrm{BMF}$ & PS \\
\hline \multicolumn{10}{|l|}{ Age } \\
\hline Education & $.08^{*}$ & & & & & & & & \\
\hline Depression & -.04 & -.04 & & & & & & & \\
\hline Anxiety & -.03 & -.04 & $.66 * *$ & & & & & & \\
\hline IA & -.04 & .04 & $.37 * *$ & $.38 * *$ & & & & & \\
\hline $\mathrm{HI}$ & $-.20 * *$ & .02 & $.26 * *$ & $.37 * *$ & $.66^{* *}$ & & & & \\
\hline SCT & $-.16 * *$ & -.04 & $.42 * *$ & $.39 * *$ & $.72 * *$ & $.59 * *$ & & & \\
\hline BMF & $-.11 * *$ & -.03 & $.30 * *$ & $.31 * *$ & $.63 * *$ & $.55^{* *}$ & $.50 * *$ & & \\
\hline PS & $-.11 * *$ & $-.10 * *$ & $.5 I^{* *}$ & $.47^{* *}$ & $.50 * *$ & $.39 * *$ & $.49 * *$ & $.39 * *$ & \\
\hline
\end{tabular}

Note: IA = inattention; $\mathrm{HI}$ = hyperactivity-impulsivity, SCT = sluggish cognitive tempo; BMF = supplemental Barkley-Murphy-Fischer ADHD criteria; $\mathrm{PS}=$ perceived stress.

$*_{p}<.05 . * * p<.01$

.79, respectively (Derogatis, 1993). The predictive validity of the BSI (Derogatis, 1993) has also been examined, with a correlation of .95 between the BSI Depression and Anxiety scales and those of the Symptom Checklist-90 (Derogatis, 1993). Coefficient alphas were derived for the 6-item Depression and Anxiety scales used in the current sample, and were similarly adequate (.87 and .78 , respectively).

\section{Procedure}

After giving informed consent, participants completed the aforementioned baseline questionnaires and rating scales, including an ADHD assessment scale based on DSM-IV-TR (APA, 2000) criteria (CSS) and items recently proposed by Barkley and colleagues (2008) as relevant to adulthood (BMF Criteria Scale) and a perceived stress measure (PSS). Questionnaires were generally administered online immediately prior to baseline, although the procedure varied slightly by cohort in that participants in Cohort 1 $(n=473)$ completed a paper-and-pencil version of the PSS at the baseline laboratory visit. In addition, approximately $10 \%$ of all participants completed surveys in a computer laboratory during their initial visit due to limited Internet access or other issues that prevented completion prior to that visit. The study procedures were reviewed and approved by the university's Institutional Review Board.

\section{Results}

Two MANOVAs were used to determine whether differences existed between the spring and fall cohorts on independent variables, Wilks's Lambda $=.98, F(8,932)=2.31$, $p=.02$, and dependent variables, Wilks's Lambda $=.43, F(5$, $975)=256.82, p<.001 .{ }^{1,2}$ Follow-up analyses indicated that the cohorts are statistically different from one another on age (an independent variable [IV] already included in Block 1 of the regression model) and perceived stress, with Cohort 2 displaying higher overall scores on both of these variables. To exert some statistical control for potential cohort differences, a dichotomous dummy variable corresponding to cohort number (coded as 1 or 2) was included in the first block of regression equations. Zero-order correlation coefficients among the continuous dependent and independent variables are presented in Table 2.

The primary planned statistical analysis was a hierarchical multiple regression on PSS score using 10 predictor variables. These putative predictors were entered in three blocks as follows: Block 1: age, gender (coded: $1=$ male, 2 = female), education level, and cohort; Block 2: BSI Depression scale and BSI Anxiety scale; and Block 3: ADHD inattentive symptoms (IA), ADHD hyperactiveimpulsive symptoms (HI), ADHD SCT symptoms, and BMF adult ADHD criteria. Each of the three hierarchical steps in the regression on perceived stress added statistically significant predictive power (see Table 3 ). The final model predicted $43 \%$ of the variance, with the third block of ADHD symptoms adding the final $10 \%$ of predictive power, $F(4,923)=40.23, p<.001$, but Block 2 contributing most substantially, $\Delta R^{2}=.29, F(2,927)=200.57, p<.001$. Eight individual independent variables emerged as statistically significant predictors in the final model. Depression $(\beta=$ $.26)$, IA $(\beta=.24)$, anxiety $(\beta=.15)$, and $\operatorname{SCT}(\beta=.12)$ symptoms were all positively associated with participants' PSS scores, and females tended to report higher perceived stress as compared with males (gender $\beta=.08$ ). Those with higher education scored lower on the PSS (education $\beta=$ -.08 ), as did older participants (age $\beta=-.07$ ). Finally, those included in the second cohort indicated more stress than peers in the first (cohort $\beta=.15$ ).

\section{Exploratory Analysis}

To facilitate more direct examination of whether clinically significant ADHD symptoms are associated with higher 
Table 3. Summary of Hierarchical Regression Predicting Perceived Stress Scores.

\begin{tabular}{lrrrrrr}
\hline & $b$ & $\beta$ & $t$ & $P$ & $R^{2}$ & $R^{2}$ \\
\hline Block I & & & & & $.05^{* * *}$ & - \\
$\quad$ Age & -0.05 & -.12 & -3.67 & $<.001$ & & \\
Education & -0.21 & -.09 & -2.81 & .005 & & \\
Gender & 1.32 & .10 & 3.13 & .002 & & \\
$\quad$ Cohort & 2.01 & .16 & 4.87 & $<.001$ & & \\
Block 2 & & & & & $.34^{* * *}$ & $.29 * * *$ \\
Depression & 0.22 & .35 & 9.94 & $<.001$ & & \\
Anxiety & 0.14 & .24 & 6.65 & $<.001$ & & \\
Block 3 & & & & & $.43^{* * *}$ & $.10 * * *$ \\
$\quad$ Inattention & 0.38 & .24 & 5.68 & $<.001$ & & \\
Hyp/Imp & -0.02 & -.01 & -.24 & .814 & & \\
SCT & 0.43 & .12 & 3.11 & .002 & & \\
BMF & 0.10 & .04 & 1.19 & .236 & & \\
\hline
\end{tabular}

Note: $\mathrm{Hyp} / \mathrm{lmp}=$ hyperactivity-impulsivity; $\mathrm{SCT}$ = sluggish cognitive tempo; BMF = supplemental Barkley-Murphy-Fischer ADHD criteria. $* * * p<.001$.

PS, participants were identified who reported markedly elevated self-reported ADHD traits (i.e., above the clinical cutoff for 30-49-year-olds per Barkley \& Murphy, 2006, total ADHD score $\geq 24$ [ $\geq 93$ rd percentile]; $n=47$ ), as were those with normal range scores (i.e., $\leq 70$ th percentile, total ADHD score $\leq 16 ; n=784$ ). An ANCOVA, controlling for BSI anxiety and depression, revealed a statistically significant difference between these groups, $F(1,826)=40.79, p$ $<.001$, of meaningful size (partial $\varepsilon^{2}=.05$; Ferguson, 2009), such that the elevated ADHD group reported substantially higher PSS (estimated marginal $M=17.99,95 \%$ confidence interval $[\mathrm{CI}]=[16.46-19.51])$ than their nonelevated counterparts $(M=12.88,95 \% \mathrm{CI}=[12.52-13.24]$; see Figure 1).

\section{Discussion}

Overall, these results indicate that specific dimensions of ADHD symptomatology influence perceived stress, and, importantly, that their influence is substantial even when taking potential demographic differences and depressive and anxious symptomatology into consideration. Consistent with the stated hypothesis, IA and SCT emerged as statistically significant predictors in this community-recruited adult sample. However, $\mathrm{HI}$ and the recently proposed BMF criteria did not. Results from exploratory analyses comparing individuals with and without elevated total ADHD symptoms further reinforced that ADHD traits are robustly and positively associated with PSS in this adult community sample. A more detailed consideration of these findings follows.

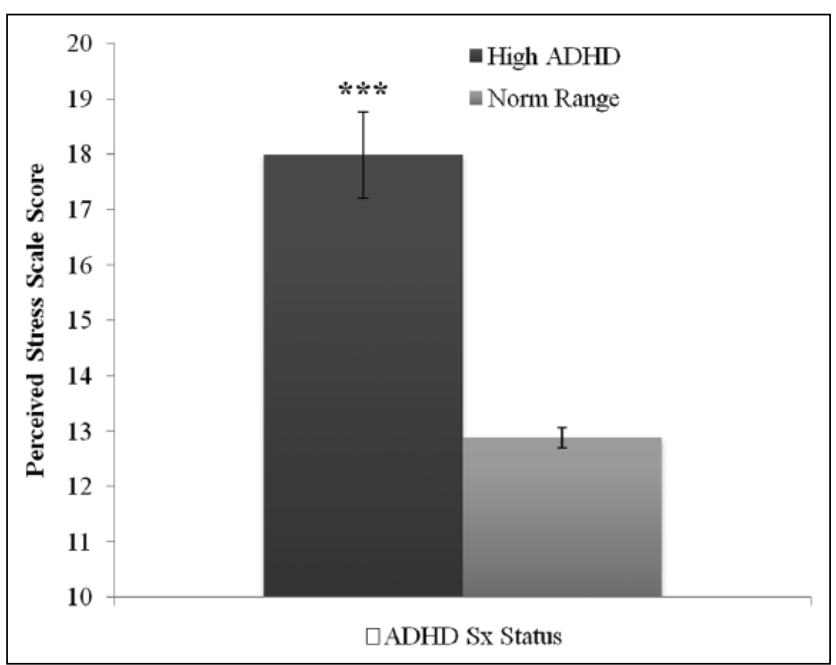

Figure I. PSS estimated marginal means comparison for elevated ADHD $(n=47)$ and normal range $(n=784)$ groups Note: PSS = Perceived Stress Scale; $S x=$ symptoms. Error bars depict upper and lower bounds of $95 \%$ confidence interval (standard error $=$ $0.78,0.18$ in elevated ADHD and normal range groups, respectively). Observed range of PSS in the sample was 0 to 38. $* * * p<.001$.

\section{ADHD-Related IA Effects}

The finding that IA was associated with higher perceived stress complements previous research that demonstrated links between an ADHD diagnosis and higher physiological and subjective stress (Hirvikoski et al., 2009; Lackschewitz et al., 2008); higher occurrence of life stressors, such as financial strain due to medical costs and behavioral interventions (Friedrichs et al., 2012; Riley, Lyman, et al., 2006); and diminished ability to cope effectively with daily stressors (Riley, Spiel, et al., 2006). However, it should be noted that previous research has not considered the independent associations of the two primary ADHD symptom clusters to stress. Thus, the results of the present research build on previous studies by suggesting that the relation between ADHD and stress in adults is driven primarily by IA.

\section{ADHD-Related HI Effects}

Conversely, HI did not emerge as a predictor for perceived stress in this study. Considering the well-established, negative impact of ADHD on stress levels (Barkley, 2006; Canu \& Carlson, 2007; Riley, Spiel, et al., 2006; Waring \& Lapane, 2008), it is somewhat surprising that HI did not impact perceived stress, as did IA. Given that the sample used in this study consisted of adults, and recognizing that IA traits are more likely than $\mathrm{HI}$ to persist into adulthood (see review in Barkley, 2006), perhaps there was a lower 
proportion of individuals who truly had impairing levels of HI that would best predict broad impairment. As a followup, an examination of the distribution of scores in this sample using the norms of a substantially younger sample referenced by Barkley and Murphy (1996; vs. current participants' $M$ age $=45.56$ years) was conducted to gauge the prevalence of persistently elevated HI and IA. The percentage of individuals in the sample who met these conservative criteria for elevated IA symptoms (i.e., $+1.5 S D$ above the $17-29$-year-old norm) was $4.4 \%$, whereas only $1.3 \%$ reported elevated HI symptoms, supporting the assumption that $\mathrm{HI}$ is less prevalent than IA in later life. Overall, although there are theoretically sound explanations for HI's nonassociation with the variable examined in this study, its lack of predictive power remains surprising given extant research suggesting the symptoms of $\mathrm{HI}$ to be impairing in multiple domains of functioning.

\section{SCT Effects}

SCT also significantly predicted higher levels of perceived stress. Given the numerous associations between ADHD and stress (Lackschewitz et al., 2008; Riley, Spiel, et al., 2006) and the link between IA and stress, in particular (see above), this finding is not surprising. The recognized symptoms of SCT (e.g., sluggishness, drowsiness, confusion, daydreaming) are unlikely to be associated with highintensity reactions to stress but may affect ability to perceive and adaptively respond to stressors, a difficulty already recognized for individuals with ADHD in general and ADHD-IA specifically (Riley, Spiel, et al., 2006). ADHD traits have been associated with a lack of persistence in response to challenges and failure (Milich, 1994). Individuals with SCT are likely to have an inadequate response to stressors and may therefore develop a kind of learned helplessness and further diminished attempts to address stressors. Although SCT has been linked largely to ADHD-IA (McBurnett, Pfiffner, \& Frick, 2001), some have suggested that SCT marks a disorder that is distinct from ADHD altogether (Barkley, 2011; Milich et al., 2001). Should such a distinction be supported by future research, the current findings linking SCT to experienced stress, independent of IA's predictive power, would help to establish the impairing effects of a SCT-indexed disorder. Clearly, however, ample room remains for further research to better define the exact relationship between SCT and stress.

\section{Effects of the BMFAdult ADHD Criteria}

Barkley and colleagues' (2008) adult ADHD criteria, which putatively map onto executive dysfunction, did not significantly predict perceived stress in this sample. The items included in these six newly identified adult ADHD symptoms (e.g., ineffectively inhibiting responses, exercising poor judgment, failing to deploying attention selectively, not adhering to directions) do overlap, to a degree, with impairment that is traditionally characteristic of $\mathrm{HI}$ and, particularly, IA. Considering the aforementioned negative links between inattentive symptoms and perceived stress, it would seem reasonable for the BMF criteria to have some significant impact on the dependent variable. However, given that the BMF scale score may overlap significantly with such $D S M-I V$-TR constructs, perhaps its influence is effectively "watered down" when entered simultaneous to $\mathrm{HI}$ and IA in a regression model.

Content of the Barkley adult ADHD items may also help to explain their nonsignificance in this study. For example, it would not be expected that completing things out of order or driving faster than others would greatly impact an individual's perceived stress outcomes. Therefore, these items may effectively indicate ADHD in adulthood (see exception in Fedele et al., 2010) but not themselves be particularly good at predicting perceived stress. However, it is important to consider that these criteria possibly relate to other aspects of stress that were not well captured by the PSS (e.g., stress related to automobile citations and related legal troubles). Future studies should more closely examine the relation of the newly proposed Barkley adult ADHD criteria to various life outcomes and adult domains of adjustment.

\section{Limitations and Future Directions}

Although the results of this study are relevant to the theory, diagnosis, and treatment of ADHD and its negative impact on several life outcomes, there are limitations that should be considered when interpreting these findings. Diversity of the sample was limited, consisting of predominantly Caucasian (95.3\%) and most having completed at least some postsecondary education $(81.6 \%)$. Future research might productively examine whether the findings of this study can be replicated among a more diverse sample.

In addition, Cohort 1 was administered by a paper-and-pencil version of the PSS, whereas Cohort 2 completed it online. As previously mentioned, MANOVA analyses indicated significant differences between cohorts on this dependent variable, a possible outcome of inconsistent instrumentation in administration. However, it should be noted that cohort was included as a predictor variable in the first predictor block, which should have afforded some statistical control for such a systematic difference between the cohorts' procedures. Furthermore, ADHD symptomatology was not found to differ across cohorts, which also protects against corruption of the statistical analyses reported herein regarding the prediction of perceived stress.

To consider the generalizability of the current findings, an informal post hoc examination of the levels of BSI-indexed 
anxiety and depression in the sample was conducted. A comparison of the $T$-score distribution in our sample indicates a similar curve as in the general nonpsychiatric population, with $S D$ s approximately at 10 and the means very close to, but slightly above, 50. Although the means and standard deviations are not that different from the norm, a visual examination suggests that the distributions are slightly positively skewed. Therefore, the prevalence of anxiety and depression in this sample is comparable with nonpsychiatric norms, and lends some confidence to the generalizability of these findings.

Further examination of the generalizability of the findings of this study included informal comparison of PSS scores of this sample with published norms. The level of perceived stress in the current sample, $M(S D)=13.69$ (6.39), appears comparable with the young adult norm population for the PSS: males $M(S D)=12.1(5.9)$ and females $M(S D)=13.7$ (6.6; Cohen et al., 1983). Therefore, it appears that the levels of perceived stress of the current sample are analogous to that of a more general population, lending further support for generalizability. However, the presence of current life stressors (e.g., divorce, death of a loved one, losing a job) may also influence an individual's level of perceived stress, and in this study, these types of stressors were not controlled or measured, something that future research could improve on.

Finally, as previously mentioned, the percentage of participants who met conservative criteria for elevated (i.e., $\geq 93$ rd percentile) IA symptoms was $4.4 \%$, whereas $1.3 \%$ reported elevated $\mathrm{HI}$. These rates are comparable with the prevalence of ADHD in adults as determined by epidemiological research (e.g., Kessler et al., 2006). However, one must acknowledge that some of these individuals, identified by self-report only, would not technically meet criteria for ADHD if a rigorous clinical interview or multiple-informant approach was used - which is the desired standard for diagnosis. The true prevalence of ADHD in the elevated ADHD group used in the exploratory analysis, which was similarly identified using self-report, is likewise uncertain. Despite the clear difference on PSS between this group and their normal range counterparts, it is still difficult to estimate how closely these findings may generalize to the general population and its subgroup of adults with ADHD, at large. Future research considering stress and health outcomes in the adult ADHD population would benefit from using more thorough diagnostic procedures to ensure accurate determination of actual ADHD diagnostic status. Such investigations might also examine whether third variables mediate the relationship between ADHD and stress, such as emotional dysregulation and job or relational instability.

\section{Declaration of Conflicting Interests}

The author(s) declared no potential conflicts of interest with respect to the research, authorship, and/or publication of this article.

\section{Funding}

The author(s) disclosed receipt of the following financial support for the research, authorship, and/or publication of this article: This work was supported by grants from the Quercegen Pharma and Coca Cola corporations.

\section{Notes}

1. When Bonferroni procedures were applied to all analyses reported herein, statistical significance did not vary. As such, further mention of these corrections is omitted.

2. Assumptions for all analyses (i.e., multicollinearity, homoscedasticity, linear function assumptions, homogeneity of covariance, normal distribution of dependent variables) were met.

\section{References}

Able, S. L., Johnston, J. A., Adler, L. A., \& Swindle, R. W. (2007). Functional and psychosocial impairment in adults with undiagnosed ADHD. Psychological Medicine, 37, 97-107. doi:10.1017/S0033291706008713

American Psychiatric Association. (2000). Diagnostic and statistical manual of mental disorders (4th ed.). Arlington, VA: Author.

Bagwell, C. L., Molina, B. S., Pelham, W. E., \& Hoza, B. (2001). Attention-deficit hyperactivity disorder and problems in peer relations: Predictions from childhood to adolescence. Journal of the American Academy of Child \& Adolescent Psychiatry, 40, 1285-1292.

Barkley, R. A. (2006). Attention-deficit hyperactivity disorder: A handbook for diagnosis and treatment (3rd ed.). New York, NY: Guilford.

Barkley, R. A. (2011). Distinguishing sluggish cognitive tempo from attention-deficit/hyperactivity disorder in adults. Journal of Abnormal Psychology. doi:10.1037/a0023961

Barkley, R. A., \& Murphy, K. (2006). Attentiondeficit hyperactivity disorder: A clinical workbook (3rd ed.). New York, NY: Guilford.

Barkley, R. A., Murphy, K., \& Fischer, M. (2008). ADHD in adults: What the science says. New York, NY: Guilford.

Beitchman, J. H., Inglis, A., \& Schachter, D. (1992). Child psychiatry and early intervention: IV. The externalizing disorders. Canadian Journal of Psychiatry, 7, 245-249.

Biederman, J., Faraone, S. V., Taylor, A., Sienna, M., Williamson, S., \& Fine, C. (1998). Diagnostic continuity between child and adolescent ADHD: Findings from a longitudinal clinical sample. Journal of the American Academy of Child \& Adolescent Psychiatry, 37, 305-313. doi:10.1097/00004583-19980300000016

Biederman, J., Mick, E., \& Faraone, S. V. (2000). Age-dependent decline of symptoms of attention deficit hyperactivity disorder: Impact of remission definition and subtype. American Journal of Psychiatry, 157, 816-818. doi:10.1176/appi.ajp.157.5.816

Biederman, J., Petty, C., Evans, M., Small, J., \& Faraone, S. (2010). A controlled 10-year follow-up study of boys with 
ADHD. Psychiatry Research, 177, 299-304. doi:10.1016/ j.psychres.2009.12.010

Birnbaum, H. G., Kessler, R. C., Lowe, S. W., Secnik, K., Greenberg, P. E., Leong, S. A., \& Swensen, A. R. (2005). Costs of attention deficit-hyperactivity disorder (ADHD) in the US: Excess costs of persons with ADHD and their family members in 2000. Current Medical Research Opinion, 21, 195-206. doi:10.1185/030079904X20303

Blase, S. L., Gilbert, A. N., Anastopoulos, A. D., Costello, E. J., Hoyle, R. H., Swartzwelder, H. S., \& Rabiner, D. L. (2009). Selfreported ADHD and adjustment to college. Journal of Attention Disorders, 13, 297-309. doi:10.1177/1087054709334446

Canu, W. H., \& Carlson, C. L. (2004). ADHD and social adaptation: From childhood to adulthood. ADHD Report, 12, 1-6.

Canu,W.H., \& Carlson, C.L.(2007). Rejection sensitivity and social outcomes of young adult men with ADHD. Journal of Attention Disorders, 10, 261-275. doi:10.1177/1087054706288106

Carlson, C. L., \& Mann, M. (2002). Sluggish cognitive tempo predicts a different pattern of impairment in the attention-deficit/ hyperactivity disorder, Predominantly Inattentive type. Journal of Clinical Child and Adolescent Psychology, 31, 123-129. doi:10.1207/153744202753441738

Chhabildas, N., Pennington, B. F., \& Willcutt, E. G. (2001). A comparison of the neuropsychological profiles of the DSM-IV subtypes of ADHD. Journal of Abnormal Child Psychology, 29, 529-540. doi:10.1023/A:1012281226028

Cohen, S. (2005). Keynote presentation at the eighth international congress of behavioral medicine: The Pittsburg common cold studies: Psychosocial predictors of susceptibility to respiratory infections diseases. International Journal for Behavioral Medicine, 12, 123-131. doi:10.1207/s15327558ijbm1203

Cohen, S., Kamarck, T., \& Mermelstein, R. (1983). A global measure of perceived stress. Journal of Health and Social Behavior, 24, 385-396. doi:10.2307/2136404

Cohen, S., Tyrrell, D. A. J., \& Smith, A. P. (1993). Negative life events, perceived stress, negative affect, and susceptibility to the common cold. Journal of Personality and Social Psychology, 64, 131-140. doi:10.1037/0022-3514.64.1.131

Dallman, M. F., Pecoraro, N.,Akana, S. F., LaFleur, S. E., Gomez, F., Houshyar, H., \& . . Manalo, S. (2003). Chronic stress and obesity: A new view of "comfort food." Proceedings of the National Academy of Sciences of the United States of America, 100, 11696-11701. doi:10.1073/pnas.1934666100

Davis, C., Levitan, R. D., Smith, M., Tweed, S., \& Curtis, C. (2006). Associations among overeating, overweight, and attention-deficit/hyperactivity disorder: A structural equation modeling approach. Eating Behaviors, 7, 266-274. doi:10.1016/ j.eatbeh.2005.09.006

Derogatis, L. R. (1993). Brief Symptom Inventory (BSI): Administration, scoring, and procedures manual. Minneapolis, MN: Pearson.

Fedele, D. A., Hartung, C. M., Canu, W. H., \& Wilkowski, B. M. (2010). Potential symptoms of ADHD for emerging adults. Journal of Psychopathology and Behavioral Assessment, 32, 385-396. doi:10.1007/s10862-009-9173-x
Ferguson, C. J. (2009). An effect size primer: A guide for clinicians and researchers. Professional Psychology: Research and Practice, 40, 532-538. doi:10.1037/a0015808

Friedrichs, B., Igl, W., Larsson, H., \& Larsson, J.-O. (2012). Coexisting psychiatric problems and stressful life events in adults with symptoms of ADHD - A large Swedish population-based study of twins. Journal of Attention Disorders, 16, 13-22. doi: $10.1177 / 1087054710376909$

Gaub, M., \& Carlson, C. L. (1997). Behavioral characteristics of DSM-IV ADHD subtypes in a school-based population. Journal of Abnormal Child Psychology, 25, 103-111. doi:10.1023/A:1025775311259

Goble, A., \& Le Grande, M. (2008). Do chronic psychological stressors accelerate the progress of cardiovascular disease? Stress and Health, 24, 203-212. doi:10.1002/smi.1202

Hartman, C. A., Wilcutt, E. G., Rhee, S. H., \& Pennington, B. F. (2004). The relation between sluggish cognitive tempo and DSM-IV ADHD. Journal of Abnormal Child Psychology, 32, 491-503. doi:10.1023/B:JACP.0000037779.85211.29

Hill, R. B., \& Petty, G. C. (1995). A new look at selected employability skills: A factor analysis of the occupational work ethic. Journal of Vocational Education Research, 20, 59-73.

Hirvikoski, T., Lindholm, T., Nordenstrom, A., Nordstrom, A., \& Lajic, S. (2009). High self-perceived stress and man stressors, but normal diurnal cortisol rhythm, in adults with ADHD (attention-deficit/hyperactivity disorder). Hormones and Behaviors, 55, 418-424. doi:10.1016/j.yhbeh.2008.12.004

Hoza, B., Mrug, S., Gerdes, A. C., Hinshaw, S. P., Bukowski, W. M., Gold, J. A., \& . . . Arnold, L. E. (2005). What aspects of peer relationships are impaired in children with attentiondeficit/hyperactivity disorder? Journal of Counseling and Clinical Psychology, 73, 411-423. doi:10.1037/0022-006X.73.3.411

Kemeny, M. E., \& Schedlowski, M. (2007). Understanding the interaction between psychosocial stress and immune-related diseases: A stepwise progression. Brain, Behavior, and Immunity, 21, 1009-1018. doi:10.1016/j.bbi.2007.07.010

Kessler, R. C., Adler, L., Barkley, R. O., Biederman, J., Connors, C. K., \& Demler, O. (2006). The prevalence and correlates of ADHD in the United States: Results from the National Comorbidity Survey Replication (NCS-R). American Journal of Psychiatry, 163, 716-723. doi:10.1176/appi.ajp.163.4.716

Lackschewitz, H., Huther, G., \& Kroner-Herwig, B. (2008). Physiological and psychological stress responses in adults with attention deficit/hyperactivity disorder (ADHD). Psychoneuroendocrinology, 33, 612-624. doi:10.1016/j.psyneuen. 2008.01.016

Lange, G., Sheerin, D., Carr, A., Dooley, B., Barton, V., Marshall, D., \& ... Doyle, M. (2005). Family factors associated with attention deficit hyperactivity disorder and emotional disorders in children. Journal Of Family Therapy, 27, 76-96. doi:10.1111/j.1467-6427.2005.00300.x

Lavoie, J. A., \& Douglas, K. S. (2012). The Perceived Stress Scale: Evaluating configural, metric and scalar invariance across mental health status and gender. Journal of 
Psychopathology and Behavioral Assessment, 34, 48-57. doi:10.1007/s10862-011-9266-1

Lazarus, R. S. (1993). From psychological stress to the emotions: A history of changing outlooks. Annual Review of Psychology, 44, 1-21. doi:10.1146/annurev.ps.44.020193.000245

Loe, I. M., Balestrino, M. D., Phelps, R. A., Kurs-Lasky, M., Chaves-Gnecco, D., Paradise, J. L., \& Feldman, H. M. (2008). Early histories of school-aged children with attention-deficit/ hyperactivity disorder. Child Development, 79, 1853-1868. doi:10.1111/j.1467-8624.2008.01230.x

McBurnett, K., Pfiffner, L. J., \& Frick, P. J. (2001). Symptom properties as a function of ADHD type: An argument for continued study of sluggish cognitive tempo. Journal of Abnormal Child Psychology, 29, 207-213. doi:10.1023/A:1010377530749

McConaughy, S. H., Volpe, R. J., Antshel, K. M., Gordon, M., \& Eiraldi, R. B. (2011). Academic and social impairments of elementary school children with attention deficit hyperactivity disorder. School Psychology Review, 40, 200-225.

Milich, R. (1994). The response of children with ADHD to failure: If at first you don't succeed, do you try, try, again? School Psychology Review, 23, 11-28.

Milich, R., Balentine, A. C., \& Lynam, D. R. (2001). ADHD Combined type and ADHD Predominantly Inattentive type are distinct and unrelated disorders. Clinical Psychology: Science and Practice, 8, 463-488. doi:10.1093/clipsy.8.4.463

Reaser, A., Prevatt, F., Petscher, Y., \& Proctor, B. (2007). The learning and study strategies of college students with ADHD. Psychology in the Schools, 44, 627-638. doi:10.1002/pits.20252

Riley,A., Lyman, L., Spiel, G., Dopfner, M., Lorenzo, M., \& Ralston, S. ADORE Study Group. (2006). The family strain index (FSI). Reliability, validity, and factor structure of a brief questionnaire for families of children with ADHD. European Child Adolescent Psychiatry, 15, 72-78. doi:10.1007/s00787-006-1010-0

Riley, A., Spiel, G., Coghill, D., Dopfner, M., Falissard, B., Lorenzo, M., \& Ralston, S. J. (2006). Factors related to healthrelated quality of life (HRQoL) among children with ADHD in Europe at entry into treatment. European Child Adolescent Psychiatry, 15, 38-45. doi:10.1007/s00787-006-1006-9

Sibley, M. H., Pelham, W. E., Molina, B., Gnagy, E. M., Waxmonsky, J. G., Waschbusch, D. A., \& Kuriyan, A. B. (2012). When diagnosing ADHD in young adults emphasize informant reports, DSM items, and impairment. Journal of Consulting and Clinical Psychology. Advance online publication. doi:10.1037/a0029098

Simon, N. M., Smoller, J. W., McNammara, K. L., Maser, R. S., Zalta, A. K., Pollack, M. H., \& Wong, K. (2006). Telomere shortening and mood disorders: Preliminary support for a chronic stress model of accelerated aging. Biological Psychiatry, 60, 432-435. doi:10.1016/j.biopsych.2006.02.004

Sobanski, E., Schredl, M., Kettler, N., \& Alm, B. (2008). Sleep in adults with attention deficit hyperactivity disorder (ADHD) before and during treatment with methylphenidate: A controlled polysomnographic study. Sleep, 31, 375-381.

Taylor, S. E. (2006). Health psychology (6th ed.). New York, NY: McGraw-Hill.

Waring, M. E., \& Lapane, K. L. (2008). Overweight in children and adolescents in relation to attention-deficit/hyperactivity disorder: Results from a national sample. Pediatrics, 122, 1-6. doi:10.1542/peds.2007-1955

Weiss, G., Hechtman, L., Milroy, T., \& Perlman, T. (1993). Hyperactive children grown up (2nd ed.). New York, NY: Guilford.

Wender, P. H. (1995). Attention-deficit-hyperactivity-disorder in adults. Oxford, UK: Oxford University Press.

Whalen, C., Jamner, L., Henker, B., Delfino, R., \& Lozano, J. (2002). The ADHD spectrum and everyday life: Experience sampling of adolescent moods, activities, smoking, and drinking. Child Development, 73, 209-227. doi:10.1111/14678624.00401

Young, S., \& Gudjonsson, G. (2006). ADHD symptomatology and its relationship with emotional, social, and delinquency problems. Psychology, Crime \& Law, 12, 463-471. doi:10.1080/ 10683160500151183

\section{Author Biographies}

Martha A. Combs, M.A., earned her Master's in clinical-health psychology at Appalachian State University in 2010, and is currently a clinical psychology doctoral student at the University of Alabama. Her primary research focus is stress-related health outcomes in clinical populations and the utilization of mindfulness as a psychosocial intervention.

Will H. Canu, Ph.D., is an associate professor in the Department of Psychology at Appalachian State University. His research focuses on the manifestation, assessment, and treatment of ADHD and related maladjustment, with a primary interest in adult outcomes.

Joshua J. Broman-Fulks, Ph.D. is an associate professor in the Department of Psychology at Appalachian State University. His research focuses primarily on the identification, prevention, and treatment of anxiety-related psychopathology.

Courtney A. Rocheleau, $\mathrm{PhD}$, is an assistant professor in the Department of Psychology at the Metropolitan State University of Denver. Her research interests are in the area of social health psychology.

David C. Nieman, DrPH, is a professor in the College of Health Sciences at Appalachian State University, and Director of the Human Performance Laboratory at the North Carolina Research Campus. His research focuses on lifestyle-immunology relationships. 